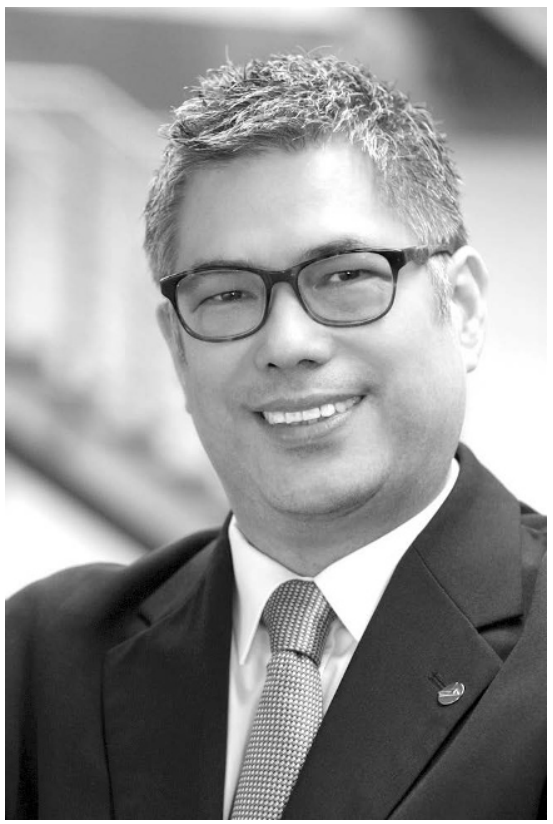

\title{
Vertrauen ist die Basis für Digitale Souveränität
}

"You can't claim trust, you have to earn it every day," sagte Microsoft-Chef Satya Nadella auf der Hausmesse Inspire im Sommer 2019. Vertrauen kann man als Unternehmen nicht für sich einfach reklamieren, man muss es sich verdienen, und zwar jeden Tag aufs Neue. Wie wichtig Vertrauen für ihn ist, beschreibt er in seinem - übrigens sehr lesenswerten - Buch "Hit Refresh: Wie Microsoft sich neu erfunden hat und die Zukunft verändert." Die Entwicklung des Microsoft-Börsenkurses seit seinem Amtsantritt scheint inm recht zu geben.

Dass Vertrauen ist tatsächlich der Anfang von allem ist, wusste und sagte eine deutsche Bank bereits in den 1980er Jahren. Allerdings verspielte sie seitdem viel Vertrauen in den vergangenen Jahren - mit entsprechenden Folgen für Mitarbeiter und Börsenkurs. Gerade in unserer seit Jahren viel zitierten VUKA-Welt, in der alles so volatil, unsicher, komplex, und ambigue ist, also mehrdeutig und missverständlich, geht es zunehmend und letztlich um einen einzigen entscheidenden Faktor: Vertrauen. Wem vertraue ich? Bei wem habe ich ein gutes Gefühl, ob als Bürger, als Unter-nehmer, als Staat?

Was digital sein kann, wird über kurz oder lang digital - weil die Nutzer es so wollen. Die umfassende digitale Trans-formation verändert Geschäftsmodelle und Arbeitsweisen grundlegend. Diese geht mit einem enormen Zuwachs an Daten, Warenverkehr und Mobilität einher. Das sorgt einerseits für mehr Komfort für die Nutzer, erhöht jedoch zugleich die Komplexität. Viele Anwender fühlen sich oder sind überfordert. "Manche spötteln, dass Verbraucher heu-te schon ein Fulltimejob ist", sagte der heutige Staatssekretär im Bundesjustizministerium Gerd Billen vor einigen Jahren, als er noch Vorstand beim Verbraucherzentrale Bundesverband war.

Um in der digitalen Welt zurechtkommen, rufen viele Nutzer, rufen wir alle nach IT-Sicherheit. Hier gilt jedoch aus meiner Erfahrung: Viel wichtiger als technisch umgesetzte Informationssicherheit ist das bereits erwähnte Vertrauen. Vertrauen als Alleinstellungsmerkmal - neudeutsch gern als Unique Selling Proposition (USP) abgekürzt - einer Lösung oder Dienstleistung kann nicht programmiert werden. Ver-trauen ist das Ergebnis eines vieldimensionalen Prozesses, der eben auch technische Aspekte beinhaltet. Daher geht in diesem Heft - und auch in diesem Editorial - um folgende Fragen: Wie entsteht Vertrauen? Welche Parameter spielen bei der Vertrauensbildung eine wesentliche Rolle - und was hat digitale Souveränität damit zu tun?

Meine zentrale These lautet also: Der Kern des Vertrauens in digitale Prozesse - und damit letztlich die Basis für die digitale Souveränität - kann nicht selbst digital sein!

\section{Kim Nguyen}

